\title{
Empirical Analysis of Commercial Housing Sales Based on EARCH(1,1) Model
}

\author{
Shichang Shen, Chao Feng \\ School of Mathematics and Statistics, Qinghai Nationalities University, Xining, China \\ Email: 13909785766@163.com
}

How to cite this paper: Shen, S.C. and Feng, C. (2019) Empirical Analysis of Commercial Housing Sales Based on $\operatorname{EARCH}(1,1)$ Model. Open Journal of Statistics, 9, 299-307. https://doi.org/10.4236/ojs.2019.92021

Received: April 4, 2019

Accepted: April 25, 2019

Published: April 28, 2019

Copyright (C 2019 by author(s) and Scientific Research Publishing Inc. This work is licensed under the Creative Commons Attribution International License (CC BY 4.0).

http://creativecommons.org/licenses/by/4.0/

\begin{abstract}
Since the 1980s, China's commercial housing market has shown an unprecedented rapid development, and the commercial houses still has a high price. This paper studies the sales rate of commercial housing sales to find an appropriate model, and it analyzes the volatility of the commercial housing market to describe the sustainable development of the commercial housing market. By selecting month data of China's commercial housing sales from January 2006 to October 2018, this paper uses EViews7.2 and the ARMA Model as the tool in order to establish $\operatorname{EARCH}(1,1)$ through the method of quantitative analysis. It is found that the yield of commercial housing sales has obvious cluster, asymmetry and leverage effect, and the impact of adverse news on the commercial housing market is more significant than the impact of favorable news.
\end{abstract}

\section{Keywords}

Sales Volume of Commercial Housing, ARMA Model, EARCH Model, Leverage Effect

\section{Introduction}

In recent years, China's development rate has been very rapid, and the people's living standards have also been significantly improved. China's commercial housing market has ushered in an unprecedented period of development especially in the context of the establishment of a comprehensive well-off society. Many domestic scholars have conducted a lot of researches for the future development prospects of the commercial housing market. Wei Junjia and Zhang Chi [1] (2014) explored the commercial housing in Nanning through the method of cointegration analysis and stationarity analysis. Shi Huiling [2] (2018) used the cross-sectional data of commercial housing sales and GDP in 30 provinces to 
explore the relationship between commercial housing prices and economic development. Zheng Lan [3] (2006) used the VAR model to discuss the transmission effect of monetary policy in the commercial housing market. Tian Tian and Dong Weijuan [4] (2009) studied the impact of macroeconomics on the demand for commercial housing. None of the above documents have studied the volatility of commercial housing market. This paper establishes commodity housing sales rate of return sequence and also makes a series of quantitative analysis of the residual of the model in order to EARCH model. The development status of China's commercial housing sales market is analyzed, and relevant suggestions are put forward as a reference.

\section{Theoretical Basis}

\subsection{ARCH Effect Test}

If the random perturbation term of the subject model $a_{t}-\mathrm{ARCH}(q)$ [5], the regression equation can be established:

$$
a_{t}=\alpha_{0}+\alpha_{1} a_{t-1}^{2}+\cdots+\alpha_{q} a_{t-q}^{2}
$$

The null hypothesis and alternative hypothesis to be tested are:

$$
\begin{aligned}
& H_{0}: \alpha_{1}=\alpha_{2}=\cdots=\alpha_{q}=0 \\
& H_{1}: \exists \alpha_{i} \neq 0(1 \leq i \leq q)
\end{aligned}
$$

Test statistic

$$
L M=n R^{2} \sim \chi^{2}(q)
$$

where, $n$ is the number of sample data; $R^{2}$ is the determinant of the auxiliary regression formula. When significance level $\alpha$ and degree of freedom $q$ are known, if $L M>\chi_{\alpha}^{2}(q)$, the null hypothesis is not accepted, indicating that there is ARCH effect in this sequence. Otherwise, there is no ARCH effect.

\subsection{EARCH Model}

The EARCH model is also called exponential GARCH model, which was proposed by Nelson [6] in 1991. The conditional variance expression of the model is:

$$
\log \left(h_{t}\right)=\alpha_{0}+\sum_{j=1}^{p} \theta_{j} \log \left(h_{t-j}\right)+\sum_{i=1}^{q}\left[\alpha_{i}\left|\frac{\varepsilon_{t-i}}{\sqrt{h_{t-i}}}\right|+\varphi_{i} \frac{\varepsilon_{t-i}}{\sqrt{h_{t-i}}}\right]
$$

where the expression of $h_{t}$ is:

$$
h_{t}=\alpha_{0}+\alpha_{1} \varepsilon_{t-1}^{2}+\cdots+\alpha_{q} \varepsilon_{t-q}^{2}
$$

If $\varphi \neq 0$, the information function is asymmetric. When $\varphi$ is less than 0 , leverage is significant.

\subsection{Skewness}

The skewness measures the symmetry of the data. Normal distribution has a 
skewness of 0 , the right is positive, and the left is negative. The calculation formula of the skewness is as follows:

$$
S=\frac{\frac{1}{n} \sum_{i=1}^{n}\left(x_{i}-\bar{x}\right)^{3}}{\left(\frac{1}{n} \sum_{i=1}^{n}\left(x_{i}-\bar{x}\right)^{2}\right)^{\frac{3}{2}}}
$$

\subsection{Kurtosis}

The kurtosis measures the flatness of the data distribution. The large data distribution at the tail has a large kurtosis value. The normal distribution has a kurtosis value of 3. Its formula is as follows:

$$
K=\frac{\frac{1}{n} \sum_{i=1}^{n}\left(x_{i}-\bar{x}\right)^{4}}{\left(\frac{1}{n} \sum_{i=1}^{n}\left(x_{i}-\bar{x}\right)^{2}\right)^{2}}
$$

\subsection{Standard Deviation}

The standard deviation can reflect the degree of dispersion of the data set, and the calculation formula is as follows:

$$
S=\sqrt{\frac{1}{n-1} \sum_{i=1}^{n}\left(x_{i}-\bar{x}\right)^{2}}
$$

\section{Empirical Analysis of ARCH Model}

This paper takes the data of China's commercial housing sales from January 2006 to October 2018 as the sample time series, and conducts data analysis with the help of EViews7.2 [7] [8]. In order to study the ARCH model of commodity housing sales, the ARMA model is used to make an empirical analysis of China's commodity housing market by determining the return rate sequence of commodity housing sales and the required sequence must be stable. The data comes from China statistical yearbook (2018).

\subsection{Data Preprocessing}

It can be seen from Figure 1 (commercial housing sales) that the sales volume of commercial housing presents an exponential trend on the whole. The annual December is much larger than the annual January, showing seasonal influence. And the unit root test is further used (Table 1).

According to the results in Table 1, the ADF (Augmented Dickey-Fuller test statistic) value is 0.358366 . At the significance level of $1 \%$, the sequence accepts the original false, and the $\mathrm{P}$ value (Probable value) is 0.9805 . It is believed that the unit root exists in the sequence $X_{t}$ indicating that the commercial housing sales volume sequence is a non-stationary time series.

In order to study the sequence of commercial housing sales, relevant data are 
XT (Commercial housing sales)

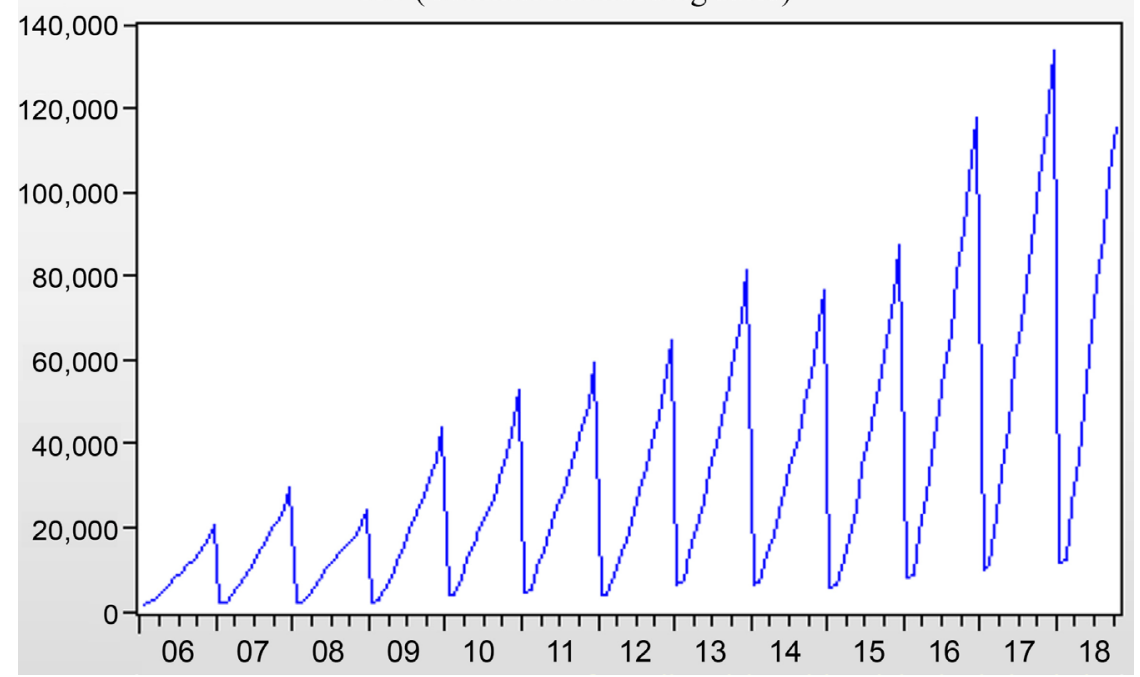

Figure 1. Time series diagrams of $X_{t}$

Table 1. Unit root test.

\begin{tabular}{cccc}
\hline & & $t$-Statistic & Prob.* $^{*}$ \\
\hline Augmented Dickey-Fuller test statistic & & 0.358366 & 0.9805 \\
& $1 \%$ level & -3.477144 & \\
Test critical values & $5 \%$ level & -2.881978 & \\
& $10 \%$ level & -2.577747 & \\
\hline
\end{tabular}

processed as follows: two first-order and one seasonal difference were performed on the data, respectively eliminating the exponential trend and seasonal influence of the sequence, so that the new yield sequence obtained does not have the correlation trend and periodic influence, and at this time, the yield sequence is a stationary sequence.

It can be seen from Figure 2 that the sequence $R_{t}$ is stable, and the continuity and clustering of the sequence can be observed.

According to the results in Table 2, the ADF value is -8.295501 . At the significance level of $1 \%$, the sequence does not accept the null hypothesis, and the $\mathrm{P}$ value is 0 . It is believed that there is no unit root in the sequence $R_{p}$ indicating that the rate of return at this time is a stable time series.

\subsection{Normality Test}

Calculate each statistic for the new sequence, as known in Table 3.

Table 3 lists the results of statistics of the return rate of commercial housing sales $R_{t}$ in which the skewness is -0.488687 , less than 0 , indicating the existence of left-deviation phenomenon of the return rate sequence. The kurtosis value was 15.75282 , while the kurtosis value of the normal distribution was 3 , which was much higher than its range value, indicating that the sequence $R_{t}$ had a distribution of "sharp peak and fat tail". The value of the J-B statistic is 954.2733 , 
RT

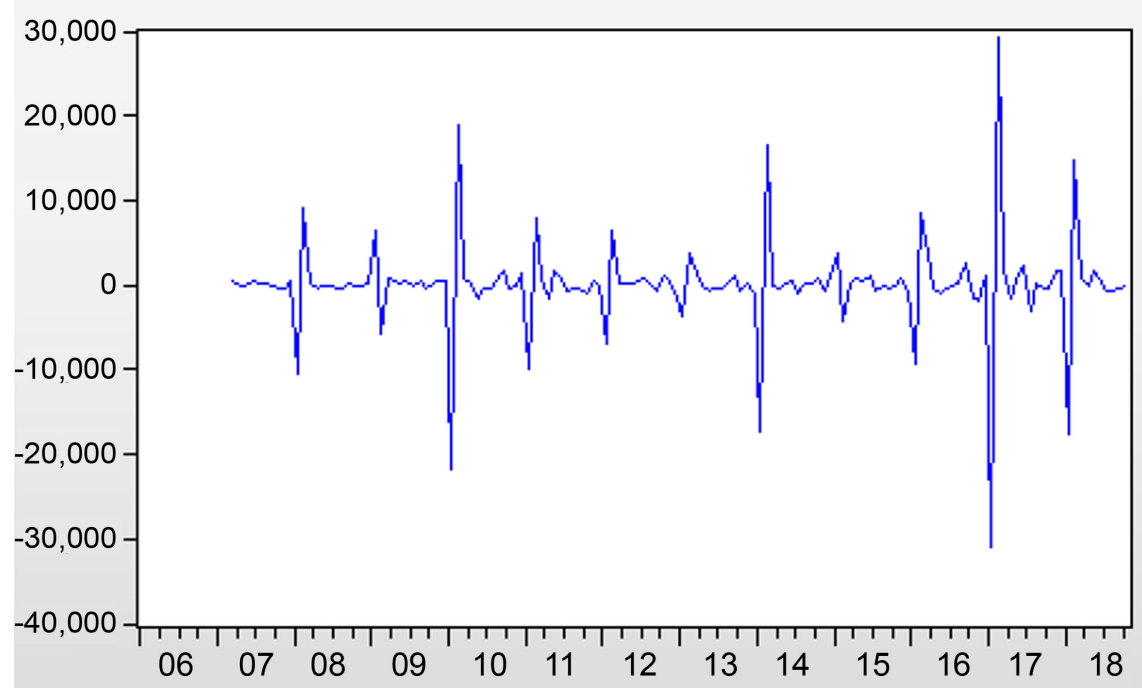

Figure 2. Time series diagrams of $R_{t}$.

Table 2. Unit root test.

\begin{tabular}{cccc}
\hline & & $t$-Statistic & Prob. $^{*}$ \\
\hline Augmented Dickey-Fuller test statistic & & -8.295501 & 0.0000 \\
& $1 \%$ level & -2.583011 & \\
Test critical values & $5 \%$ level & -1.943324 & \\
& $10 \%$ level & -1.615075 & \\
\hline
\end{tabular}

Table 3. $R_{t}$ sequence statistics.

\begin{tabular}{ccccccccc}
\hline Mean & Median & Maximum Minimum & Std. Dve & Skewness & Kurtosis & Jarque-Bera & Prob. \\
\hline 5.038071 & 72.28000 & 29126.21 & -30987.50 & 5735.344 & -0.488687 & 15.75282 & 954.2733 & 0.0000 \\
\hline
\end{tabular}

and its $\mathrm{P}$ value is 0 , indicating that the sequence $R_{t}$ does not obey the normal distribution.

\subsection{ARCH Effect Test}

In order to study the relationship within the return sequence $R_{t}$ ARMA (auto-regressive moving average) model is taken as the main model, $\operatorname{ARMA}(2,0)$ was finally determined as the subject model by analyzing the autocorrelation and partial autocorrelation graphs of the yield $R_{t}$ series, as known in Table 4 .

Its parameters are estimated as follows:

$$
R_{t}=-0.636409 R_{t-1}-0.339977 R_{t-2}+a_{t}
$$

The sequence autocorrelation LM (Lagrange Multiplier) test for the random perturbation term $a_{t}$ of the equation $R_{t}$ obtained a $\mathrm{P}$ value of 0.0034 , indicating the existence of autocorrelation in the sequence. Next, the author performs the autocorrelation LM test with order 7 on the sequence, as known in Table 5. 
Table 4. Parameter estimation of sequence $R_{t}$.

\begin{tabular}{ccccc}
\hline Variable & Coefficient & Std. Error & t-Statistic & Prob. \\
\hline $\operatorname{AR}(1)$ & -0.636409 & 0.080644 & -7.891617 & 0.0000 \\
$\operatorname{AR}(2)$ & -0.339977 & 0.080644 & -4.215772 & 0.0000 \\
\hline
\end{tabular}

Table 5. LM test for the sequence $R_{t}$.

\begin{tabular}{cccc}
\hline F-statistic & 3.673805 & Prob. F(7,131) & 0.0012 \\
\hline $\mathrm{Obs}^{\star} R$-squared & 22.93780 & Prob. Chi-Square(7) & 0.0017 \\
\hline
\end{tabular}

It can be seen from Table 5 that the p-value of the seventh-order statistic is 0.0017 , less than 0.01 , indicating that the random perturbation term $a_{t}$ sequence of the ARMA model has an autocorrelation, and it has the high order ARCH effect, so the return rate sequence $R_{t}$ can build the GARCH model.

\subsection{Model Recognition}

GARCH $(1,1)$ model should be selected to fit the high-order ARCH effect in the yield sequence $R_{t}$ and other types of ARCH effect models should be fitted. Table 6 lists $\operatorname{GARCH}(1,1), \operatorname{GARCH}-\mathrm{M}(1,1), \operatorname{TARCH}(1,1), \operatorname{EARCH}(1,1)$, logarithmic likelihood function values, AIC values and SC values of the return sequence $R_{t}$.

According to Table 6, the rate of return sequence $R_{t}$ is more suitable for EARCH $(1,1)$ model under AIC (Akaike Information Criterion) and SC (Schwarz Criterion) criteria, and its value reaches the minimum, which is 19.68798 and 19.81525 respectively. Meanwhile, the value of the logarithmic likelihood function is the largest, and the value is -1352.471 . Therefore, the fitting model $\operatorname{EARCH}(1,1)$ is finally determined.

It can be seen from Table 7 that all $\mathrm{P}$ values of the coefficients of $\operatorname{EARCH}(1,1)$ model are 0 , indicating good fitting effect:

$$
\begin{aligned}
& \text { Mean value equation: } R_{t}=-0.266744 R_{t-1}-0.312926 R_{t-2}+a_{t} \\
& \log \left(h_{t}\right)=9.414443+0.450156 \log \left(h_{t-1}\right) \\
& \text { Variance equation: } \\
& -0.524599 \frac{\left|a_{t-1}\right|}{\sqrt{h_{t-1}}}-0.775541 \frac{a_{t-1}}{\sqrt{h_{t-1}}}
\end{aligned}
$$

According to the variance equation, the parameters $\alpha_{0}=9.41443$ and $\theta_{1}=0.450156$ are both greater than 0 , indicating that the fluctuation of income is positive and in line with the actual situation of commercial housing sales today. the asymmetric coefficient $\varphi_{1}=-0.775541$ is less than 0 , indicating that the fluctuation phenomenon of the rate of return on sales of commercial housing in China is asymmetric, when $\alpha_{1}+\varphi_{1}=-1.30014$, it shows the impact when there is good news, when $\alpha_{1}-\varphi_{1}=0.250942$, it shows the impact of bad news.

\subsection{Adaptability Test}

The ARCH effect test is performed by the sequence in the variance equation to 
Table 6. Model identification.

\begin{tabular}{cccc}
\hline & Log likelihood & AIC & SC \\
\hline GARCH $(1,1)$ & -1362.626 & 19.82066 & 19.92672 \\
GARCH-M(1,1) & -1362.581 & 19.83451 & 19.96178 \\
TARCH $(1,1)$ & -1361.514 & 19.81904 & 19.94632 \\
EARCH $(1,1)$ & -1352.471 & 19.68798 & 19.81525 \\
\hline
\end{tabular}

Table 7. Parameter estimation of EARCH model.

\begin{tabular}{|c|c|c|c|c|}
\hline Variable & Coefficient & Std. Error & z-Statistic & Prob. \\
\hline $\operatorname{AR}(1)$ & -0.266744 & 0.078224 & -3.410007 & 0.0000 \\
\hline $\operatorname{AR}(2)$ & -0.312926 & 0.073357 & -4.265780 & 0.0000 \\
\hline \multicolumn{5}{|c|}{ Variance Equation } \\
\hline$\alpha_{0}$ & 9.414443 & 2.679488 & 3.513576 & 0.0000 \\
\hline$\alpha_{1}$ & -0.524599 & 0.098770 & -5.311333 & 0.0000 \\
\hline$\varphi_{1}$ & -0.775541 & 0.126619 & -6.124994 & 0.0000 \\
\hline$\theta_{1}$ & 0.450156 & 0.157640 & 2.855585 & 0.0000 \\
\hline$R$-squared & 0.192206 & \multicolumn{2}{|c|}{ Mean dependent var } & 1.457194 \\
\hline Adjusted $R$-squared & 0.192206 & \multicolumn{2}{|c|}{ S.D. dependent var } & 5755.930 \\
\hline S.E. of regression & 5173.277 & \multicolumn{2}{|c|}{ Akaike info criterion } & 19.68798 \\
\hline Sum squared resid & $3.69 \mathrm{E}+09$ & \multicolumn{2}{|c|}{ Schwarz criterion } & 19.81525 \\
\hline Log likelihood & -1352.471 & \multicolumn{2}{|c|}{ Hannan-Quinn criterion } & 19.20105 \\
\hline Durbin-Watson stat & 2.579847 & & & \\
\hline Inverted AR Roots & -0.29 & & & \\
\hline
\end{tabular}

find out whether this effect has been eliminated. Figure 3 is an autocorrelation and partial autocorrelation test of the standard deviation residual sequence of the EARCH $(1,1)$ model of the sales rate of commercial housing in China.

It can be seen from Figure 3 that the $\mathrm{P}$ value is 0.017 when proceeding to the fifth step, and the autocorrelation hypothesis that the significance level is 0.01 standard deviation residual sequence is rejected, indicating that the residual sequence has no ARCH effect. It may be reasonable to establish an $\operatorname{EARCH}(1,1)$ model. Next, ARCH effect test can be performed on the residual sequence.

It can be seen from Table 8 that the P value of LM statistic is 0.7131, greater than 0.01 , which further indicates that the $\mathrm{ARCH}$ effect no longer exists in the residual sequence. Therefore, fitting $\operatorname{EARCH}(1,1)$ model is appropriate.

\section{Conclusion}

This paper mainly studies the characteristics of the return rate of commercial housing sales and finds that the return rate sequence has ARCH effect, and $\operatorname{EARCH}(1,1)$ model is still effective. From 2006 to 2018, China's commercial housing sales have witnessed unprecedented rapid development. What's more, 


\begin{tabular}{|c|c|c|c|c|c|c|}
\hline Autocorrelation & Partial Correlation & & $A C$ & PAC & Q-Stat & Prob \\
\hline$\square$ & $\square$ । & 1 & -0.213 & -0.213 & 6.4595 & \\
\hline 다 & $\square 1$ & 2 & -0.184 & -0.241 & 11.314 & 0.001 \\
\hline 1 1 & I 1 & 3 & 0.027 & -0.081 & 11.422 & 0.003 \\
\hline 10 & 吅 1 & 4 & -0.048 & -0.119 & 11.760 & 0.008 \\
\hline 101 & 吅 1 & 5 & -0.040 & -0.105 & 11.993 & 0.017 \\
\hline וך ו & $1 \mid 1$ & 6 & 0.068 & -0.006 & 12.672 & 0.027 \\
\hline 1 & 1 & 7 & -0.013 & -0.033 & 12.699 & 0.048 \\
\hline 1 & 1 & 8 & -0.015 & -0.021 & 12.733 & 0.079 \\
\hline $1 \mid 1$ & 1 & 9 & -0.000 & -0.025 & 12.733 & 0.121 \\
\hline 叫 1 & 吅 1 & 10 & -0.109 & -0.138 & 14.527 & 0.105 \\
\hline
\end{tabular}

Figure 3. Correlation diagram of standard deviation residual sequence.

Table 8. ARCH effect test results of sequence.

\begin{tabular}{cccc}
\hline F-statistic & 0.133377 & Prob. F(1,136) & 0.7155 \\
\hline Obs $^{*} R$-squared & 0.135206 & Prob. Chi-Square(1) & 0.7131 \\
\hline
\end{tabular}

the fluctuation of the return rate of commercial housing sales is positive, and the leverage effect coefficient of model is negative, indicating that the fluctuation of China's commercial housing sales is asymmetric and has significant leverage effect. At the same time, by analyzing the variance equation of the model, it can be seen that the rate of return on sales of commercial housing has a more significant response to adverse news. In other words, adverse factors in the market have a greater impact on commercial housing market. With the increase of favorable news, the commercial housing market will eventually level off. Through the above empirical analysis, several suggestions can be made for the development of the commercial housing market. The government can regulate and control the commercial housing market; it can increase good news that is conducive to market development. Buyers can determine the purchase intention according to the price increase. The government should adopt policy measures in the commodity housing market to steadily increase sales and consolidate the development of the commercial housing market.

\section{Funds}

This work is supported by the National Natural Science Foundation of China (No. 11561056) and Natural Science Foundation of Qinghai (No. 2016-ZJ-914).

\section{Conflicts of Interest}

The authors declare no conflicts of interest regarding the publication of this paper.

\section{References}

[1] Wei, J.J. and Zhang, C. (2014) Empirical Analysis on the Influencing Factors of 
Commercial Housing Sales in Nanning City. Economic and Social Development, 12, 16-19.

[2] Shi, H.L. (2018) Empirical Analysis of Real Estate Price and Economy-Based on Sectional Data Analysis of Commodity Housing Sales and Gross Domestic Product in 30 Provinces. Era Economy and Trade, 7, 57-58.

[3] Zheng, L. (2006) Research on Monetary Policy Transmission Effect in Real Estate Market Based on VAR Model. Hunan University Press, Changsha.

[4] Tian, T. and Dong, W.J. (2009) Research on the Impact of Macroeconomic Changes on the Demand for Commercial Housing. Modern Economic Information, 9, 54-55.

[5] Engle, R.F. (1982) Autoregressive Conditional Heteroscedaticity with Estimates of the Variance of U.K. Inflation. Econometrica, 50, 987-1007. https://doi.org/10.2307/1912773

[6] Nelson, D.B. (1991) Conditional Heteroskedasticity in Asset Returns: A New Approach. Econometrica, 59, 347-370. https://doi.org/10.2307/2938260

[7] Gao, T.M. (2009) Econometric Analysis Methods and Modeling-EViews Applications and Examples. 2nd Edition, Tsinghua University Press, Beijing.

[8] Yi, D.H. (2008) Data Analysis and Application of Eviews. China Renmin University Press, Beijing. 